\title{
For 481 biomedical open access journals, articles are not searchable in the Directory of Open Access Journals nor in conventional biomedical databases.
}

Mads S Liljekvist, Kristoffer Andresen, Hans-Christian Pommergaard, Jacob Rosenberg

Background: Open access (OA) journals allows access to research papers free of charge to the reader. Traditionally, biomedical researchers use databases like MEDLINE and EMBASE to discover new advances. However, biomedical OA journals might not fulfil such databases' criteria, hindering dissemination. The Directory of Open Access Journals (DOAJ) is a database exclusively listing OA journals. The aim of this study was to investigate DOAJ's coverage of biomedical OA journals compared with the conventional biomedical databases.

Methods: Information on all journals listed in four conventional biomedical databases (MEDLINE, PubMed Central, EMBASE and SCOPUS) and DOAJ were gathered. Journals were included if they were 1 ) actively publishing, 2) full $O A, 3$ ) prospectively indexed in one or more database, and 4) of biomedical subject. Impact factor and journal language were also collected. DOAJ was compared with conventional databases regarding the proportion of journals covered, along with their impact factor and publishing language. The proportion of journals with articles indexed by DOAJ was determined.

Results: In total, 3,236 biomedical OA journals were included in the study. Of the included journals, $86.7 \%$ were listed in DOAJ. Combined, the conventional biomedical databases listed $75.0 \%$ of the journals; $18.7 \%$ in MEDLINE; $36.5 \%$ in PubMed Central; $51.5 \%$ in SCOPUS and $50.6 \%$ in EMBASE. Of the journals in DOAJ, $88.7 \%$ published in English and $20.6 \%$ had received impact factor for 2012 compared with $93.5 \%$ and $26.0 \%$, respectively, for journals in the conventional biomedical databases. A subset of $51.1 \%$ and $48.5 \%$ of the journals in DOAJ had articles indexed from 2012 and 2013, respectively. Of journals exclusively listed in DOAJ, one journal had received an impact factor for 2012 , and $59.6 \%$ of the journals had no content from 2013 indexed in DOAJ.

Conclusions: DOAJ is the most complete registry of biomedical OA journals compared with five conventional biomedical databases. However, DOAJ only indexes articles for half 
of the biomedical journals listed, making it an incomplete source for biomedical research papers in general. 


\section{Authors:}

3 Mads Svane Liljekvist ${ }^{1}$,

4 Kristoffer Andresen ${ }^{1}$,

5 Hans-Christian Pommergaard ${ }^{1}$,

6 Jacob Rosenberg ${ }^{1}$

7

8 Affiliation:

$9 \quad{ }^{1}$ Department of Surgery, Herlev Hospital, University of Copenhagen, Denmark 
10

11 The idea of open access (OA) in the field of scientific research is to create a publishing platform where

12 knowledge is freely available for all (The Budapest Open Access Initiative 2002) and not bound by

13 commercial interests (Giglia 2007). From 1993 to 2009 the number of published OA articles increased

14 from less than 250 to more than 191,000 articles a year. In 2008, OA articles constituted an estimated

$1520 \%$ of all scholarly articles published in that year (Bjork et al. 2010; Laakso et al. 2011). OA research papers can be deposited in online archives (repositories), published in OA journals or both (Bjork et al. 2010). OA research papers can be published with (most OA journals) or without being peer reviewed (e.g. private or institutional repositories and journals exercising post-publication peer review - i.e. F1000Research). The idea of peer reviewed OA journals combines free availability with the benefits of traditional, scholarly communication and editorial - quality control through peer review processes.

In the field of biomedical research, both subscription-based and OA journals are listed in online databases such as MEDLINE and EMBASE as well as archived in online repositories such as PubMed Central (Table 1). These databases index articles published in the listed journals which can be searched via different online search engines, e.g. PubMed or Ovid. PubMed searches more than 23 million citations from journals primarily in MEDLINE or PubMed Central, as well as citations from journals in the U.S. National Library of Medicine's (NLM) catalogue and books from the National Center for Biotechnology Information (NCBI) Bookshelf (U.S. National Library of Medicine 2002).

Journal applications to a database are sorted and selected according to strict selection criteria (Peña et al. 2004; U.S. National Library of Medicine 1988; U.S. National Library of Medicine 2014d). The above-mentioned databases all evaluate subject, regularity and standard formal requirements, such as whether the applying periodical can be considered a scientific journal. However, some biomedical OA journals might presently be unable to comply with more specific selection criteria. For example, 
33 complying with technical demands like those set by PubMed Central (U.S. National Library of

34 Medicine 2014d) can be costly for small, independent journals. PubMed Central requires all full text

35 articles to be submitted in specific Document Type Definition (DTD), eXtensible Markup Language

36 (XML) format and tagged with the correct values for a number of identifiers (U.S. National Library of

37 Medicine 2014c). For evaluation of the journal, a sample package of selected articles is submitted in

38 the XML format. Similarly, for indexing in MEDLINE, XML-tagged data for each article abstract and

39 citation are required for submitted articles (U.S. National Library of Medicine 1990). Current inclusion

40 in MEDLINE automatically qualifies a journal for inclusion in PubMed Central (U.S. National Library

41 of Medicine 2014d). The NIH-chartered committee, the Literature Selection Technical Review

42 Committee (LSTRC), determines selection for MEDLINE by evaluating the journals' editorial and

43 production quality, quality of the journals' content as well as the journals standing and contribution to

44 its field (U.S. National Library of Medicine 1988). The NLM's Library Operations Division (LOD)

45 determines selection for PubMed Central based on the Collection Development Manual of the National

46 Library of Medicine (U.S. National Library of Medicine 2004). PubMed Central includes journals

47 which are not included in MEDLINE and can therefore be interpreted as more comprehensive than

48 MEDLINE. However, the specific parameters of evaluation are not evident from PubMed Central's

49 Scientific Quality Standard (U.S. National Library of Medicine 2014d). EMBASE selects its journals

50 based on scientific quality and editorial coverage. SCOPUS's Content Selection \& Advisory Board

51 (CSAB) selects journals by evaluating their journal policy, quality, standing, regularity and

52 availability. Elsevier, owning both SCOPUS and EMBASE, converts submitted articles to a

53 standardized XML DTD when received from the journal (Elsevier 2015).

55 regards to selection and indexing of their content in these biomedical databases and repositories, even 
56 if these journals publish high quality papers - hence making them hard to find for readers. This may

57 create a barrier for readers, thus hindering timely and wide dissemination of research and

58 compromising the purpose of OA (Access 2003). The Directory of Open Access Journals (DOAJ)

59 (Directory of Open Access Journals 2014c) was founded in 2003 and, at the time of this study, listed

60 more than 9,700 OA journals. Supplying articles for indexation is optional and currently more than

615,600 of the journals are searchable at the article level. DOAJ aims to cover all OA journals regardless

62 of scientific subject (Directory of Open Access Journals 2014a) and lists journals that target academic

63 researchers by primarily publishing research papers (Directory of Open Access Journals 2014f). For

64 inclusion in DOAJ, full text papers must be made available to the readers in full and for free

65 immediately upon publication (Directory of Open Access Journals 2014f). Journals must have

66 transparent access policies and exercise peer review (Directory of Open Access Journals 2014f).

67 However, DOAJ does not evaluate the journals' standing, contribution and whether their papers are

68 "important" (Directory of Open Access Journals 2014f). Therefore, DOAJ offers a window for newly

69 established OA journals to get indexed in an online database - thereby facilitating the access to papers

70 published in OA journals.

The purpose of this study was to investigate the distribution and overlap of biomedical

72 OA journals between DOAJ and "conventional biomedical databases".

\section{Methods}

\section{Databases}

76 In this study, we investigated the content of the OA-specific DOAJ and a number of databases and

77 repositories that are not OA-specific. These databases and repositories are specified below and will be 
78 referred to as the "conventional biomedical databases". DOAJ is not regarded as "conventional" as it

79 only indexes OA journals, unlike the rest of the included databases. In order to investigate the

80 distribution of biomedical OA journals between DOAJ and the conventional biomedical databases, we

81 retrieved journal lists from DOAJ and the following four conventional biomedical databases:

82 MEDLINE, PubMed Central (PMC), EMBASE and SCOPUS (Table 1). Furthermore, data from the

83 Journal Citation Reports (JCR) 2012 Science and Social Sciences edition were downloaded and

84 included. Data from the U.S. National Library of Medicine (NLM) journal catalogue was also included

85 to identify journals found in PubMed, which were not indexed by either MEDLINE or PMC (U.S.

86 National Library of Medicine 2002). Data on activity, OA-status, publication language and 2012-

87 impact factor were collected from the four databases and Journal Citation Reports.

\section{Data collection and inclusion criteria}

90 Journal lists were freely available from the websites of DOAJ, EMBASE (including a listing of

91 MEDLINEs journals), SCOPUS, PubMed Central and NLM and were retrieved in May 2014. Data

92 from JCR was retrieved using institutional access via the University of Copenhagen in January 2014.

93 Access to the content of EMBASE and SCOPUS are subject to an institutional subscription as well, 94 even though a subscription is not necessary to access their journal lists.

96 (ISSN) or Electronic ISSN (EISSN). Journal records listed without either of these were excluded. All

97 journals were cross-matched on ISSN and EISSN, so journals with ISSN incorrectly registered as

98 EISSN (and vice versa), were correctly matched. 
The dataset was constructed by merging the databases' journal lists, and aggregating data

100 for matching journals. Figure 1 illustrates the process. From this comprehensive list a sample of

101 journals was drawn following four inclusion criteria: Only journals that were 1) actively publishing, 2)

102 releasing all content free of charge immediately upon publication (full and immediate OA), 3)

103 prospectively indexed in one or more of the included conventional databases and/or DOAJ and 4)

104 considered to be of biomedical subject were included in the study.

The study only included actively publishing journals. Since manual collection of

106 information on the latest issue from every journal was deemed too labour intensive, the following

107 database denotations for activity were used: For journals listed in SCOPUS, each was labelled as

108 "active/inactive" in the journal list. No similar variable was available for journals in MEDLINE,

109 EMBASE or PubMed, so in order to avoid underestimating the share of active OA journals found in

110 these databases, all journals indexed in MEDLINE, EMBASE or PubMed Central were considered

111 active. Exceptions were made for journals explicitly noted as inactive by an end publication year

112 (MEDLINE, DOAJ) or a "predecessor"-status (PMC) (Fogelman 2009) as long as this was not

113 contested by information from one or more of the other databases. Where data on activity was collected

114 manually, journals were considered active if they had published at least one article in 2013 or 2014.

For this study, only journals granting full and immediate access to all content were considered to be OA journals in accordance with the Bethesda Statement on Open Access Publishing

117 (Bethesda Statement on Open Access Publishing 2003) and the DOAJ selection criteria (Directory of

118 Open Access Journals 2014f). Subscription journals with optional OA for individual articles (hybrid

119 OA), subscription journals allowing the authors to archive free versions of individual articles, journals

120 providing OA to only part of their contents (e.g. research articles only) and journals providing OA to

121 their content after an embargo period (delayed OA) were not considered full OA for the purposes of the 
122 present study. SCOPUS, DOAJ and PubMed Central provided information on OA-status. If any one of

123 these databases had labelled the journal as OA, the journal was included. For 403 actively publishing

124 journals, OA-status could not be determined via data from the downloaded journal lists. OA-statuses

125 for these journals were collected manually using the journal websites.

126

127

128

129

130

131

132

133

134

135

136

137

138

139

140 141 of biomedical subject (Embase 2014; U.S. National Library of Medicine 1988; U.S. National Library 142 of Medicine 2014b).

Since the journal must be both currently publishing and grant full and immediate OA to

all content to be eligible for inclusion in DOAJ (Directory of Open Access Journals 2014f), all journals listed in DOAJ were assumed to fulfil these two criteria - except when an end year of publication (when the journal had ceased to publish) was listed in DOAJ.

MEDLINE, PubMed Central, SCOPUS and EMBASE index the contents of their selected journals prospectively. DOAJ indexes articles prospectively when supplied by the journal. Therefore, all journals listed in DOAJ were considered as being prospectively indexed. NLM's catalogue lists titles from all of PubMed - including MEDLINE's and PMC's repertoires as the active sources for new citations. Furthermore, it lists titles no longer being indexed along with non-biomedical titles etc. (U.S. National Library of Medicine 2002). Therefore, titles exclusively listed in NLM's catalogue were not considered prospectively indexed in any of the included databases.

Both DOAJ and SCOPUS select journals from a broad spectrum of scientific fields. Only journals of a biomedical subject were included in this study. The chosen biomedical subjects from DOAJ and SCOPUS are presented in Table $\mathbf{S 1}$ and $\mathbf{S 2}$ respectively. Journals indexed in EMBASE, MEDLINE or PubMed Central were considered biomedical since these databases only index journals 
144 OA-status were collected manually via their respective websites. Journals found inactive or not full OA 145 were excluded. In total, 434 journals were left after exclusion of erroneously included journals. Furthermore, 283 journals had no language information available through the databases.

147 Languages for these journals were collected manually.

149 publication date, 10 denoted as "predecessor" and 58 denoted as "inactive" by SCOPUS). These were

150 manually checked for activity and OA-status. Nine of these journals were inactive, and were excluded.

151 All of the journals were full OA.

To determine how many of the journals indexed in DOAJ had opted to submit the

153 metadata of their contents to DOAJ, we downloaded article metadata from DOAJ's XML-based

154 metadata server (Directory of Open Access Journals 2014e). We used a modified OAI-PMH (Open

155 Access Initiative Protocol for Metadata Harvest) (Lagoze et al. 2008) C\# client for scraping the

156 required article metadata (Table S3). If any article indexed in DOAJ had a publication date in 2012 or

1572013 and carried the journal's ISSN, that journal would be marked as having their content the

158 respective year indexed in DOAJ.

\section{Data validation}

161 To validate the data, SPSS's "Random Sample" function was used to draw two samples from both the

162 excluded and the included journals followed by manual collection of specific data for the sampled

163 journals. This was done to a) make sure we had not wrongfully excluded relevant journals, and b) to

164 ensure the reliability of data for the included journals. 
166 subscription based were randomly sampled. Activity and OA-status were manually collected from the

167 NLM catalogue and the journals' respective websites. The access level of any active journal was

168 determined based on the availability of both current issue contents and archived content. Another random sample of $160(\sim 5 \%)$ included journals was drawn to verify activity, OA-status, language category, impact factor and whether the journal was indexed in DOAJ. The data was manually collected from the journal websites, JCR and DOAJ.

172

173

174 175

\section{Results}

\section{Data validation}

181 The sample of 100 excluded journals yielded 57 active journals; including 1 full OA journal 182 (Oklahoma Law Review), which was not of biomedical subject even though it was categorized under 183 'Medicine' in SCOPUS. Overall, none of the sample journals fulfilled the inclusion criteria.

184 The sample of $160(\sim 5 \%)$ included journals yielded the following: 
185

186

187

188

189

190

191

192

193

194

195

196

\section{Findings}

198

199

200

201

202

203

204

205

206

\section{Table 2.}

- All examined journals were active, full OA-journals except for 1 journal (BMC Pharmacology), which had fused with BMC Clinical Pharmacology (which had been rightly excluded) in 2012 to form another new journal. This new OA-journal was already included in our cohort and so the predecessors were removed from the cohort.

- All journals were correctly labelled as "not in DOAJ" $(n=33)$, or "in DOAJ" $(n=126)$.

- For 5 journals, language had been collected manually, since no information was available through the databases. Of the remaining 154 journals, 3 had been incorrectly labelled regarding English/non-English language.

- All journals with a 2012 impact factor $(n=33)$ had had the correct impact factor assigned during the dataset build. The remaining 126 journals had correctly been assigned no 2012 impact factor.

In total, 3,236 biomedical OA journals were included in this study. Of these, $89.2 \%$ (2,888 journals) were published in English and 19.5\% (632 journals) had received an impact factor for 2012 with a median value of 1.257, interquartile range (IQR): [0.615-2.423]. The overall journal distribution by database type (DOAJ or conventional), language (English/non-English) and impact factor is shown in

The proportions of the included OA journals listed in the respective databases are summarized in Table 3. We found that $86.7 \%$ (2,804 journals) of the included OA journals were listed in DOAJ. In contrast, each of the conventional databases accounted for lesser proportions of the study sample. Combined, the conventional biomedical databases listed $75.1 \%(2,429$ journals $)$ of the 
207 included journals - 18.7\% (605 journals) in MEDLINE, 36.5\% (1,181 journals) in PubMed Central, $20851.5 \%$ (1,667 journals) in SCOPUS and 50.6\% (1,636 journals) in EMBASE. Using PubMed to search

209 for content in OA journals (displaying results from MEDLINE, PubMed Central and NLM's Catalogue 210 combined) revealed results from a large proportion of OA journals as $56.4 \%$ (1,824 journals) are listed 211 in these three databases combined. However, 10.3\% (334 journals) were not prospectively indexed in 212 MEDLINE or PMC. These titles were listed in the NLM's catalogue and therefore did not have full or 213 current content searchable via PubMed. Hence only 46.1\% (1,490 journals) of the biomedical OA 214 journals are being prospectively indexed in full for PubMed via MEDLINE and PubMed Central. 215 Considering journals only listed in one database, the conventional biomedical databases had $3.2 \%$ (102 216 journals) uniquely listed in one of the databases (Table 3) compared to $24.9 \%$ (807 journals) only in 217 DOAJ. The overlap of journals with all of the included databases in between is illustrated in 219 Table 4. DOAJ lists between $80.9 \%$ (1,324 journals) to $87.0 \%$ (1,450 journals) of the biomedical OA 220 journals found in each of the conventional biomedical databases. Inversely, the conventional 221 biomedical databases overlapped DOAJ with between $18.4 \%$ (517 journals) and 51.7\% (1,450 222 journals).

224 journals) and the journals listed in the conventional biomedical databases (93.5\%, 2,271 journals)

225 (Table 2). However, of the 807 journals listed only in DOAJ, a smaller proportion of $76.5 \%$ (617 226 journals) were published in English. Meanwhile, 92.6\% (400 journals) of the 432 journals listed only in 227 the conventional biomedical databases were published in English. 
229 in DOAJ had received an impact factor for 2012 with a median value of 1.316, IQR: [0.619-2.456]. For

230 journals listed in the conventional biomedical databases, 26.0\% (631 journals) had received a 2012

231 impact factor with a median value of 1.263, IQR: [0.615-2.426]. Journals only listed in DOAJ and

232 journals listed only in the conventional biomedical databases had only $0.1 \%$ ( 1 journal) and $12.3 \%$ (53

233 journals) respectively with an impact factor for 2012. The impact factors were 0.372 and median 0.994 ,

234 IQR: [0.558-1.892] respectively.

235

236

237

238

Some of the journals listed in DOAJ had articles from $2012(51.1 \%, 1,434$ journals $)$ and 2013 (48.5\%, 1,359 journals) indexed in DOAJ (Table 5). Of the journals listed only in DOAJ, 40.5\% (327 journals) and 40.4\% (326 journals) had articles from 2012 and 2013 respectively indexed in DOAJ.

Twenty journals only listed in DOAJ and with no content from 2013 were randomly selected (via SPSS) and their method of dissemination further scrutinized. Of these, $90 \%$ (18 journals) had some content accessible via Google Scholar. Fifty-five per cent (11 journals) had no other databases listed on their homepages. The remaining 45\% (9 journals) listed databases including

CrossRef, Index Copernicus, SciELO, Redalyc, LatIndex, Open J-Gate and JournalSeek. All 20 journals had content available through their homepage or their publisher's homepage.

\section{Discussion}

\section{Main findings}

This study found that DOAJ lists the vast majority of biomedical OA journals and overlaps each of the conventional biomedical databases in an equal manner and also includes a number of journals not listed 
250 in the conventional biomedical databases. Even combined, MEDLINE, PMC, SCOPUS and EMBASE

251 did not match DOAJ's number of listed biomedical OA journals. Each of the conventional biomedical 252 databases listed about half of the journals relevant to this study. However, DOAJ alone did not list all 253 biomedical OA journals, leaving $13.3 \%$ of to be located elsewhere.

254

255

256

257

258

259

260

261

262

263

264

265

266

267

Both the journal subset not listed in DOAJ and the journal subset not listed in the

conventional biomedical databases were characterized by fewer journals with a 2012 impact factor and a lower median impact factor value. Only one journal outside the conventional biomedical databases had received an impact factor for 2012. To receive an impact factor, a journal must be selected for and indexed in Web of Science (WoS) where citation counts are published as impact factor via Journal Citation Reports. Before being selected for WoS, a journal is evaluated on a range of parameters similar to the conventional biomedical databases' selection criteria. These include timeliness of publication, keeping with international editorial conventions, available bibliographical information in

English and peer review processes (Testa 2012). Language was dichotomized into English/non-English and the majority of the journals listed in both the conventional biomedical databases and DOAJ were published in English. However, the lowest percentage of English-publishing journals (76.5\%) was found among journals not listed in the conventional biomedical databases but only in DOAJ. Amongst journals listed in the conventional biomedical databases, this percentage was higher (93.5\%) indicating that English-publishing journals might be favoured.

\section{Strengths and limitations}

This study focused on a single scientific field to keep "cultural" differences between the various scientific disciplines from confounding the overall picture. Several large databases were included in 
272 this study and hence a large number of potentially relevant journals were screened for inclusion in the 273 study. Four relevant inclusion criteria were applied to define the cohort from database metadata.

274 Followingly, the cohort was refined through sequential manual exclusion of ineligible journals, which 275 had been wrongfully included. The systematic inclusion of journals was based on an assumption that 276 the database data was correct. It was assumed that all journals in DOAJ were both active and full OA. 277 The activity of OA journals in DOAJ has earlier been contested (Morris 2006), where up to $14 \%$ of 278 journals were found not to be currently active. DOAJ has changed a lot since 2005 and currently uses a 279 standardized application form (Directory of Open Access Journals 2014d) along with running 280 exclusion of inactive journals (Directory of Open Access Journals 2014b). To validate the assumption, 281 and because the journals' metadata derived from all databases could be faulty, a limited data validation 282 of both included and excluded journals was conducted. This revealed high concordance between 283 database data and manually collected data, ensuring that only ineligible journals had been excluded and 284 only eligible journals had been included. One limitation of this study is that exclusively full OA 285 journals were included - e.g. excluding journals providing OA to scientific content only, journals 286 exercising delayed OA along with journals employing hybrid OA business models. One could argue 287 that inclusion of these journals would alter the results since these business models do not comply with 288 the DOAJ selection criteria (Directory of Open Access Journals 2014f). Thus these journals would not 289 contribute to the segment found in DOAJ. The study found that the majority of the included journals 290 were published in English. However, specific non-English platforms such as SciELO, Redalyc and 291 Latindex were not included. These platforms index OA journals from Latin America, the Caribbean, 292 Portugal and Spain and might contain even more biomedical OA journals not publishing in English. 


\section{Perspectives}

295 To our knowledge, this is the first study directly comparing DOAJ's amount of listed journals with that 296 of conventional biomedical databases. Earlier studies of OA publishing have utilized DOAJ as an 297 assumed complete list of OA journals, and drawn their samples from here (Dallmeier-Tiessen et al. 298 2010; Laakso \& Bjork 2012; Laakso et al. 2011). Other studies compared the attributes of some 299 conventional biomedical databases (Falagas et al. 2008; Kejariwal \& Mahawar 2012), but not the exact 300 overlap of listed journals.

302 than self-archiving for distributing OA content (Bjork et al. 2010). PubMed is the primary search 303 engine for many biomedical researchers, making the content of thousands of journals searchable, 304 including approximately 1,800 OA journals. To display OA articles only, the user can enable the "Free 305 Full Text"-filter when searching PubMed (U.S. National Library of Medicine 2014a). However, this 306 function also displays OA papers from otherwise subscription journals (hybrid OA journals) and 307 presupposes the PubMed indexer designates all relevant articles correctly. Similarly, DOAJ can be 308 searched at article level using Boolean operators. A major condition for considering DOAJ equal to the 309 conventional biomedical databases is DOAJ's indexation of individual journal articles in such a fashion 310 so that they become searchable for the readers. However, we found that only about $50 \%$ of the 311 biomedical journals had actually opted to get their articles indexed in DOAJ. This is an important fact 312 to consider, as it means DOAJ's coverage at the article level is lacking compared to the databases 313 where article indexation is a main feature - e.g. MEDLINE and PMC. With 807 biomedical OA 314 journals not reachable via the conventional biomedical databases but readily found through DOAJ, we 315 may raise the question whether searches in DOAJ should be included along the conventional PubMed 316 and EMBASE searches when conducting systematic reviews of the biomedical literature. However, as 
only about $40.5 \%$ of these journals have current content available, which is searchable through DOAJ,

318 the actual gain from searching DOAJ for individual articles could be limited. It does seem odd that

319 journals exclusive to DOAJ would be reluctant from having their content be made available and searchable. Reasons for this lack of indexed articles for these journals are only speculative at this stage. Thus, it would be interesting to search out and assess the number of conducted studies that are only found via DOAJ. This would shed light on the size of includable articles left out of the systematic reviews that do not search DOAJ. However, such an assessment is not within the scope of the present study. We found that the majority of journals without content in DOAJ or the conventional biomedical databases have some content searchable via Google Scholar. However, to what degree is uncertain, and the completeness of Google Scholar's searches have been contested (Kejariwal \& Mahawar 2012). Nearly half of the journals had no other databases listed on their websites, and thereby Google Scholar might supposedly be the only search engine, besides the journals' respective archives, where readers can find their content. as a service to readers. This makes them attractive options for journals to be listed in. However, to get indexed in a database, journals must apply to the specific database and make sure the journal fulfils the database's pre-specified selection criteria. For the conventional biomedical databases included in this study, selection criteria include the quality of content, production and home pages, along with the editorial work, the quality of peer review and evaluation of a journal's academic standing and contribution to its field. (Peña et al. 2004; Scopus 2014; U.S. National Library of Medicine 1988; U.S.

337 National Library of Medicine 2014d). Furthermore, journals applying to e.g. MEDLINE must have a minimum number of papers published and comply with the specific technical requirements mentioned earlier (Table 1) (U.S. National Library of Medicine 1988). These criteria are set in order to secure the 
user a certain level of scientific quality within the included journals and their papers, but the criteria compromise the extent to which journals can be included. DOAJ's selection criteria do not depend on evaluation of e.g. standing, contribution and layout in the same way criteria for some of the conventional biomedical databases do. DOAJ demonstrates a database model where biomedical OA journals not presently selected for the conventional biomedical databases can still have their content indexed and made available and searchable for readers, aiding wide dissemination of their content. However, of the journals in DOAJ 48.5\% (1,359 journals) had articles from 2013 indexed in DOAJ. This leaves 51.5\% (1,445 journals) with no current articles indexed in DOAJ. This lack of journals indexing their articles might have root in the fact that DOAJ requires either a manual (article by article) or XML-coded submission of article metadata to index (Directory of Open Access Journals 2015). This complicated and/or expensive workload might keep journals from heeding DOAJ's strong recommendation to upload article metadata. Furthermore, for 432 biomedical OA journals, no record in DOAJ could be found even though they are listed in one or more of the conventional biomedical databases. One can only speculate as to why these journals are not listed in DOAJ. Their publishers might be content with the attention gained from readers through the conventional biomedical databases, they might find applying for selection for DOAJ unnecessary, or they might be oblivious to DOAJ's existence.

\section{Conclusions}

The Directory of Open Access Journals lists the majority of biomedical OA journals. It also overlaps and lists more than $80 \%$ of each of the conventional biomedical databases' biomedical OA journal, and has the largest proportion of uniquely listed biomedical OA journals among the studied databases.

However, less than half of the listed journals have current content indexed in DOAJ. The conventional 
363 biomedical databases each lack around $50 \%$ of relevant biomedical OA journals and their inclusion of 364 the OA journals listed in DOAJ is sparse and unevenly distributed among the databases. 
365

366

\section{References}

Berlin Declaration on Open Access to Knowledge in the Sciences and Humanities. 2003. Available at http://openaccess.mpg.de/286432/Berlin-Declaration (accessed Jan 28 2014).

Bjork BC, Welling P, Laakso M, Majlender P, Hedlund T, and Gudnason G. 2010. Open access to the scientific journal literature: situation 2009. PLoS One 5:e11273.

The Budapest Open Access Initiative. 2002. Available at http://www.budapestopenaccessinitiative.org/read (accessed 20 November 2014).

Dallmeier-Tiessen S, Goerner B, Darby R, Hyppoelae J, Igo-Kemenes P, Kahn D, Lambert S, Lengenfelder A, Leonard C, Mele S, Polydoratou P, Ross D, Ruiz-Perez S, Schimmer R, Swaisland M, and van der Stelt W. 2010. Open Access Publishing - Models and Attributes. Available at http://edoc.mpg.de/478647 (accessed 2014 Jan 12).

Directory of Open Access Journals. 2014a. Aims \& Scope. Available at http://doaj.org/about\#aimscope (accessed 20 November 2014). Archived at http://www.webcitation.org/6UEJGSJYm.

Directory of Open Access Journals. 2014b. DOAJ publishes lists of journals removed and added. Available at https://doajournals.wordpress.com/2014/05/22/doaj-publishes-lists-of-journalsremoved-and-added/ (accessed 20 November 2014).

Directory of Open Access Journals. 2014c. The DOAJ Web Page. Available at http://doaj.org/ (accessed 20 November 2014). Archived at http://www.webcitation.org/6UEJMkDrC.

Directory of Open Access Journals. 2014d. Journal Application Form. Available at

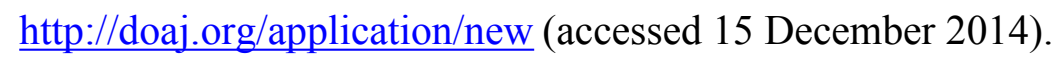

Directory of Open Access Journals. 2014e. OAI-PMH. Available at http://doaj.org/features (accessed 15 December 2014). 
387 Directory of Open Access Journals. 2014f. What are the basic standards that a journal must meet for 388 the application to be considered? Available at http://doaj.org/faq\#standards (accessed 20

Falagas ME, Pitsouni EI, Malietzis GA, and Pappas G. 2008. Comparison of PubMed, Scopus, Web of Science, and Google Scholar: strengths and weaknesses. FASEB J 22:338-342.

Fogelman M. 2009. New Version of PubMed Central ${ }^{\circledR}$ Journal List Released. Available at http://www.nlm.nih.gov/pubs/techbull/mj09/mj09_pmc_redesign.html. Archived at http://www.webcitation.org/6UPIIvZHO.

Giglia E. 2007. Open access in the biomedical field: a unique opportunity for researchers (and research itself). Eura Medicophys 43:203-213.

Kejariwal D, and Mahawar KK. 2012. Is your journal indexed in PubMed? Relevance of PubMed in biomedical scientific literature today. WebmedCentral MISCELLANEOUS 3:WMC003159.

Laakso M, and Bjork BC. 2012. Anatomy of open access publishing: a study of longitudinal development and internal structure. BMC Med 10:124.

Laakso M, Welling P, Bukvova H, Nyman L, Bjork BC, and Hedlund T. 2011. The development of open access journal publishing from 1993 to 2009. PLoS One 6:e20961. 
410 Lagoze C, Sompel HVd, Nelson M, and Warner S. 2008. The Open Archives Initiative Protocol for 411 Metadata Harvesting. Available at 412 http://www.openarchives.org/OAI/openarchivesprotocol.html (accessed 20 November 2014). 413 Archived at http://www.webcitation.org/6UEI2sypY.

414 Morris S. 2006. When is a journal not a journal? A closer look at the DOAJ. Learned Publishing $415 \quad 19: 73-76$.

416 Peña EP, Valero MV, and Sicilia JG. 2004. Comparative study of journal selection criteria used by 417 MEDLINE and EMBASE, and their application to Spanish biomedical journals. 9th European Conference of Medical and Health Libraries, Santander (Spain).

Bethesda Statement on Open Access Publishing. 2003. Available at http://legacy.earlham.edu/ peters/fos/bethesda.htm\#definition. Archived at http://www.webcitation.org/6UPIxGb1p.

Scopus. 2014. Content Coverage Guide. Available at http://www.elsevier.com/_data/assets/pdf_file/0019/148402/SC_Content-CoverageGuide July-2014.PDF (accessed 25 November 2014). Archived at http://www.webcitation.org/6UM7ncYDG.

J Testa. 2012. The Thomson Reuters journal selection process. Available at http://wokinfo.com/essays/journal-selection-process/ (accessed 22 April 2015). Archived at http://www.webcitation.org/6XyfOJ3Yn.

U.S. National Library of Medicine. 1988. Fact Sheet: MEDLINE® Journal Selection. Available at http://www.nlm.nih.gov/pubs/factsheets/jsel.html (accessed 20 November 2014). Archived at http://www.webcitation.org/6UEJNHC51. 
432 U.S. National Library of Medicine. 1990. FAQ: Journal Selection for MEDLINE® Indexing at NLM.

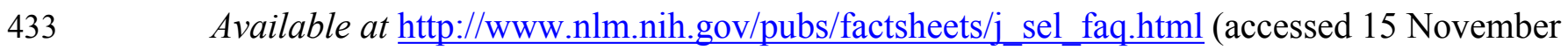
434 2014).

435 U.S. National Library of Medicine. 2002. Fact Sheet. MEDLINE, PubMed, and PMC (PubMed Central): How are they different? Available at http://www.nlm.nih.gov/pubs/factsheets/dif_med_pub.html (accessed 30 November 2014). Archived at http://www.webcitation.org/6UTfqJaUy.

U.S. National Library of Medicine. 2004. Collection Development Manual of the National Library of Medicine. Available at http://www.nlm.nih.gov/tsd/acquisitions/cdm/ (accessed 2 March 2015).

U.S. National Library of Medicine. 2014a. Free copies of some articles may be obtained in these ways. Available at http://www.ncbi.nlm.nih.gov/books/NBK3827/\#pubmedhelp.Free_copies_of_some_. Archived at http://www.webcitation.org/6UTKlw9Bh.

U.S. National Library of Medicine. 2014b. PMC Overview. Available at http://www.ncbi.nlm.nih.gov/pmc/about/intro/ (accessed 15 December 2014).

U.S. National Library of Medicine. 2014c. PMC's Technical Requirements. Available at http://www.ncbi.nlm.nih.gov/pmc/pub/pubinfo/\#tech-eval (accessed 20 November 2014).

U.S. National Library of Medicine. 2014d. PubMed Central Scientific Quality Standard. Available at http://www.ncbi.nlm.nih.gov/pmc/pub/pubinfo/\#sci-quality (accessed 20 November 2014). Archived at http://www.webcitation.org/6UEJNjire. 
1

The inclusion process of biomedical open access journals. 


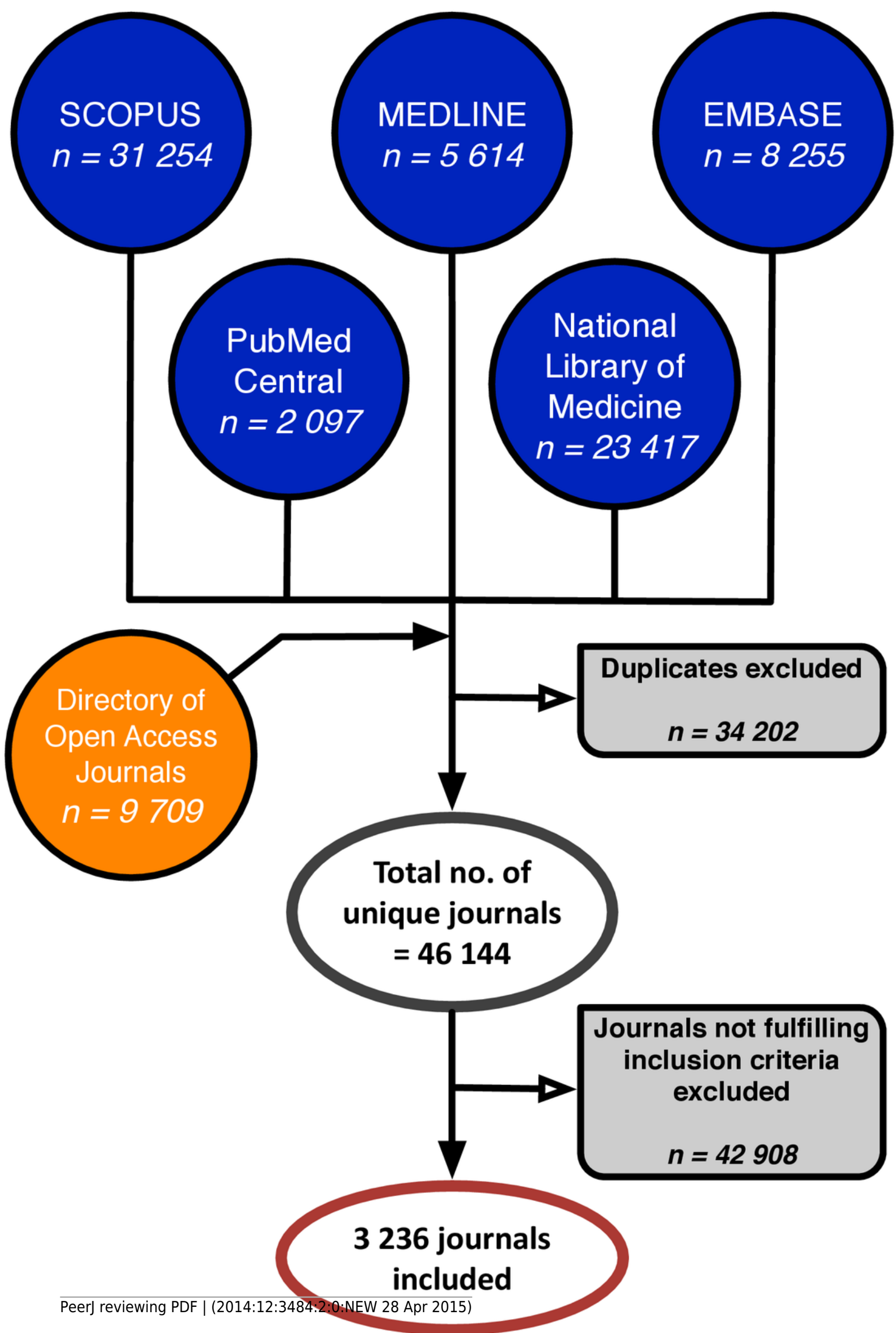




\section{Table $\mathbf{1}$ (on next page)}

Properties of the included databases.

DOAJ; Directory of Open Access Journals, MeSH; Medical Subject Headings, XML; eXtensible Markup Language. 


\begin{tabular}{|c|c|c|c|c|c|}
\hline & DOAJ & MEDLINE & PubMed Central & SCOPUS & EMBASE \\
\hline Type and size of content & 9,700 journals. & 5,600 journals. & 2,100 journals. & 34,000 journals and book series. & 8,400 journals. \\
\hline Subjects & All scientific and scholarly. & $\begin{array}{l}\text { Biomedicine and clinical } \\
\text { medicine. }\end{array}$ & $\begin{array}{l}\text { Biomedicine and clinical } \\
\text { medicine. }\end{array}$ & $\begin{array}{l}\text { Health, life, social and physical } \\
\text { sciences. }\end{array}$ & $\begin{array}{l}\text { Broad biomedicine, } \\
\text { focus on pharmacology } \\
\text { and clinical medicine. }\end{array}$ \\
\hline Journal quality control & Peer review. & Peer review. & Peer review. & Peer review. & Peer review. \\
\hline $\begin{array}{l}\text { Can be searched by } \\
\text { abstracts, authors and } \\
\text { journal title }\end{array}$ & Yes. & Yes. & Yes. & Yes. & Yes. \\
\hline $\begin{array}{l}\text { Specific, hierarchical } \\
\text { topic search available }\end{array}$ & No. & Yes (MeSH). & $\begin{array}{l}\text { Yes (MeSH - not } \\
\text { available for all entries). }\end{array}$ & $\begin{array}{l}\text { Yes (MeSH and Emtree among } \\
\text { others). }\end{array}$ & Yes (Emtree). \\
\hline Availability of content & $\begin{array}{l}\text { All content must be available } \\
\text { online. }\end{array}$ & $\begin{array}{l}\text { Either available online or in } \\
\text { print. }\end{array}$ & $\begin{array}{l}\text { Articles must be supplied } \\
\text { for archiving. }\end{array}$ & $\begin{array}{l}\text { All content must be available } \\
\text { online. }\end{array}$ & $\begin{array}{l}\text { Either available online } \\
\text { or in print. }\end{array}$ \\
\hline $\begin{array}{l}\text { Special requirements or } \\
\text { topics of evaluation }\end{array}$ & $\begin{array}{l}\text { Full and immediate open } \\
\text { access }(\mathbf{O A}) \text { to all of a } \\
\text { journal's content required. } \\
\text { Transparent OA policies, and } \\
\text { editorial }\end{array}$ & $\begin{array}{l}\text { Evaluates standing and } \\
\text { contribution. }\end{array}$ & $\begin{array}{l}\text { Evaluation based on the } \\
\text { Collection Development } \\
\text { Manual of the National } \\
\text { Library of Medicine. }\end{array}$ & $\begin{array}{l}\text { Evaluated on journal policy, } \\
\text { quality, standing, regularity and } \\
\text { availability. }\end{array}$ & $\begin{array}{l}\text { Evaluated on scientific } \\
\text { and editorial coverage. }\end{array}$ \\
\hline XML-submission & $\begin{array}{l}\text { XML-submission of full-text } \\
\text { articles optional. }\end{array}$ & $\begin{array}{l}\text { XML-submission of } \\
\text { abstracts/citations required. }\end{array}$ & $\begin{array}{l}\text { XML-submission of full- } \\
\text { text articles required. }\end{array}$ & $\begin{array}{l}\text { Database converts submission to } \\
\text { XML. }\end{array}$ & $\begin{array}{l}\text { Database converts } \\
\text { submission to XML. }\end{array}$ \\
\hline $\begin{array}{l}\text { Required age before } \\
\text { review for indexing }\end{array}$ & $\begin{array}{l}\text { None, but must publish at } \\
\text { least } 5 \text { articles per calendar } \\
\text { year, to stay indexed. }\end{array}$ & $\begin{array}{l}\text { Life span of at least } 12 \text { months } \\
\text { and } 40 \text { published articles. }\end{array}$ & $\begin{array}{l}\text { 15-30 articles published, } \\
\text { publisher dependent. }\end{array}$ & Not explicitly required. & Not explicitly required. \\
\hline $\begin{array}{l}\text { Title and abstract in } \\
\text { English required }\end{array}$ & No. & Yes. & Yes. & Yes. & Yes. \\
\hline Access cost & Free. & Free. & Free. & Institutional subscription only. & $\begin{array}{l}\text { Institutional subscription } \\
\text { only. }\end{array}$ \\
\hline Uses & $\begin{array}{l}\text { Indexes and links to journals' } \\
\text { homepages, along with } \\
\text { providing journal metadata. } \\
\text { Links to free full text articles, } \\
\text { when article data has been } \\
\text { provided by the journal. }\end{array}$ & $\begin{array}{l}\text { Links to full text articles, as well } \\
\text { as free full text (if available). }\end{array}$ & $\begin{array}{l}\text { Archives free full text } \\
\text { articles from OA journals, } \\
\text { and free articles from } \\
\text { subscription journals } \\
\text { under the NIH Grant } \\
\text { Policy. }\end{array}$ & Links to full text articles. & $\begin{array}{l}\text { Links to full text } \\
\text { articles. }\end{array}$ \\
\hline References & $\begin{array}{l}\text { Directory of Open Access } \\
\text { Journals 2014a, 2014d, 2014f } \\
\text { and } 2015 .\end{array}$ & $\begin{array}{l}\text { Falagas et al. 2008; Peña et al. } \\
\text { 2004; U.S. National Library of } \\
\text { Medicine } 1988 \text { and } 1990 .\end{array}$ & $\begin{array}{l}\text { U.S. National Library of } \\
\text { Medicine } 2014 \mathrm{c} \text {. }\end{array}$ & $\begin{array}{l}\text { Falagas et al. 2008; Scopus 2014; } \\
\text { Elsevier } 2015 .\end{array}$ & $\begin{array}{l}\text { Embase 2014; Peña et } \\
\text { al. 2004; Elsevier } 2015 .\end{array}$ \\
\hline
\end{tabular}


PeerJ Reviewing Manuscript

Peer) reviewing PDF | (2014:12:3484:2:0:NEW 28 Apr 2015) 


\section{Table 2 (on next page)}

The distribution and overall characteristics of biomedical open access journals between the Directory of Open Access Journals and the conventional biomedical databases.

Values are presented as \% ( $n$ ), if nothing else is noted.

Percentages in the first row are based on total number of journals included.

Percentages in all other rows are based on the number in journals in each group (i.e. the (n) of each columns first row).

DOA; Directory of Open Access Journals, OA; open access.

Conventional biomedical databases include: MEDLINE, PubMed Central, EMBASE, SCOPUS and U.S. National Library of Medicine. 


\begin{tabular}{|c|c|c|c|c|c|c|}
\hline & In DOAJ & Only in DOAJ & $\begin{array}{c}\text { In both DOAJ and } \\
\text { conventional } \\
\text { biomedical databases }\end{array}$ & $\begin{array}{l}\text { Only in conventional } \\
\text { biomedical databases }\end{array}$ & $\begin{array}{c}\text { In conventional } \\
\text { biomedical } \\
\text { databases }\end{array}$ & $\begin{array}{c}\text { All open access } \\
\text { journals }\end{array}$ \\
\hline $\begin{array}{l}\text { Number of biomedical OA } \\
\text { journals }\end{array}$ & $86.7(2,804)$ & $24.9(807)$ & $61.7(1,997)$ & $13.3(432)$ & $75.0(2,429)$ & $100(3,236)$ \\
\hline English language journals & $88.7(2,488)$ & $76.5(617)$ & $93.7(1,871)$ & $92.6(400)$ & $93.5(2,271)$ & $89.2(2,888)$ \\
\hline Received impact factor 2012 & $20.6(579)$ & $0.1(1)$ & $28.9(578)$ & $12.3(53)$ & $26.0(631)$ & $19.5(632)$ \\
\hline Impact factor 2012 (median & 1.316 & 0.372 & 1.320 & 0.994 & 1.263 & 1.257 \\
\hline [interquartile range]) & {$[0.619-2.456]$} & {$[0.372-0.372]$} & {$[0.619-2.458]$} & [0.558-1.892] & {$[0.615-2.426]$} & {$[0.615-2.423]$} \\
\hline
\end{tabular}




\section{Table 3 (on next page)}

The distribution of biomedical open access journals among the included databases.

Values are presented as \% (n).

$D O A$ ); Directory of Open Access Journals, $O A$; open access.

a Journals only searchable via PubMed through the National Library of Medicine's catalogue, but not prospectively indexed via MEDLINE or PubMed Central. They are included as they are prospectively indexed in one or more of the other databases. 


\begin{tabular}{llll}
\hline Database & $\begin{array}{l}\text { Journals } \\
\text { indexed }\end{array}$ & $\begin{array}{l}\text { Journals unique to } \\
\text { each database }\end{array}$ & $\begin{array}{l}\text { Journals not found in } \\
\text { DOAJ }\end{array}$ \\
\hline DOAJ & $86.7(2,804)$ & $24.9(807)$ & - \\
\hline $\begin{array}{l}\text { PubMed (search } \\
\text { engine) }\end{array}$ & $56.4(1,824)$ & $0(0)$ & $9.0(292)$ \\
\hline - MEDLINE & $18.7(605)$ & $0(0)$ & $2.7(88)$ \\
- PubMed Central & $36.5(1,181)$ & $0(0)$ & $5.4(176)$ \\
\hline - Rest of PubMed & $10.3(334)$ & - & $1.9(60)$ \\
\hline SCOPUS & $51.5(1,667)$ & $0.6(19)$ & $6.7(217)$ \\
\hline EMBASE & $50.6(1,636)$ & $2.6(83)$ & $9.6(312)$ \\
\hline
\end{tabular}




\section{Table 4(on next page)}

The overlap of biomedical open access journals between all included databases.

Values are presented as \% (n).

DOA); Directory of Open Access Journals, PMC; PubMed Central.

The table should be read with $1^{\text {st }}$ row representing the databases of origin and $1^{\text {st }}$ column as the crosschecked databases. Thus, of journals from a $1^{\text {st }}$ row database, $\%$ (n) can be found in the crosschecked $1^{\text {st }}$ column database. 
The number of journals from the $1^{\text {st }}$ row listed database -

\begin{tabular}{ccccccc}
\hline & $\begin{array}{c}\text { Database } \\
\text { name }\end{array}$ & DOAJ & EMBASE & SCOPUS & MEDLINE & PMC \\
$\begin{array}{c}\text { Which can be } \\
\text { found in the 1 }\end{array}$ & DOAJ & $\mathbf{1 0 0 . 0}(\mathbf{2 , 8 0 4 )}$ & $80.9(1,324)$ & $87.0(1,450)$ & $85.5(517)$ & $85.1(1,005)$ \\
$\begin{array}{c}\text { column listed } \\
\text { database: }\end{array}$ & EMBASE & $47.2(1,324)$ & $\mathbf{1 0 0 . 0 ( 1 , 6 3 6 )}$ & $74.4(1,241)$ & $99.3(601)$ & $67.1(793)$ \\
& SCOPUS & $51.7(1,450)$ & $75.9(1,241)$ & $\mathbf{1 0 0 . 0 ( 1 , 6 6 7 )}$ & $92.1(557)$ & $66.9(790)$ \\
\hline & MEDLINE & $18.4(517)$ & $36.7(601)$ & $33.4(557)$ & $\mathbf{1 0 0 . 0}(\mathbf{6 0 5})$ & $24.9(294)$ \\
\hline
\end{tabular}


Table 5 (on next page)

The proportion of biomedical open access journals listed in the Directory of Open Access Journals that has their content indexed at article level.

Values are presented as \% ( $n$ ).

DOAJ; Directory of Open Access Journals, OA; open access. 


\begin{tabular}{lll}
\hline Share of journals in & $51.1(1,434)$ & $48.5(1,359)$
\end{tabular}

4

DOAJ with indexed

5

articles

6

Share of the journals

$40.5(327)$

40.4 (326)

7

only found in DOAJ

8

and with articles

9

indexed herein 